\title{
Micronization of Hard Coal with the Use of a High-Pressure Water Jet
}

\author{
Przemysław J. Borkowski ${ }^{1, *(1)}$ and Wiesław Szada-Borzyszkowski ${ }^{2}$ (i) \\ 1 Faculty of Geoengineering Mining and Geology, Wroclaw University of Technology, Na Grobli 15, \\ 50-421 Wrocław, Poland \\ 2 Koszalin University of Technology, Branch of the KUT in Szczecinek, Waryńskiego 1, \\ 78-400 Szczecinek, Poland; wieslaw.szada-borzyszkowski@tu.koszalin.pl \\ * Correspondence: przemyslaw.borkowski@pwr.edu.pl; Tel.: +48-71-320-4866
}

Citation: Borkowski, P.J.;

Szada-Borzyszkowski, W. Micronization of Hard Coal with the Use of a High-Pressure Water Jet. Energies 2021, 14, 4745. https:// doi.org/10.3390/en14164745

Academic Editor: Manoj Khandelwal

Received: 7 July 2021

Accepted: 2 August 2021

Published: 4 August 2021

Publisher's Note: MDPI stays neutral with regard to jurisdictional claims in published maps and institutional affiliations.

Copyright: (c) 2021 by the authors. Licensee MDPI, Basel, Switzerland. This article is an open access article distributed under the terms and conditions of the Creative Commons Attribution (CC BY) license (https:// creativecommons.org/licenses/by/ $4.0 /)$.

\begin{abstract}
This paper presents an original method for the micronization of coal particles in a hydro-jet mill, which allows effective comminuting of coal in the pressure range of 100-250 MPa, at a variable water flow rate of $0.2-0.5 \mathrm{dm}^{3} / \mathrm{s}$. The discussed high-pressure water jet mill (HPWJM) allows the comminution of standard fines, with a grain size up to $2 \mathrm{~mm}$, and at a relatively high comminuting efficiency of 8 to $55 \mathrm{~g} / \mathrm{s}$. In addition, the paper presents energy-consumption ratios, and indicates the advantage of this method over mechanical grinding in a planetary ball-mill. At optimum conditions, coal comminution at an efficiency of $Q_{c}=38.4 \mathrm{~g} / \mathrm{s}$ and at an energy input of $E_{H}=1.1 \mathrm{MJ} / \mathrm{kg}$ provides an average particle size of about $40 \mu \mathrm{m}$. The degree of comminution was further improved by applying roto-turbulent micronization, which resulted in an average size of comminuted coal particles of only $17 \mu \mathrm{m}$. As an additional result, the actual surface area of the particles increased by 10-30 thousand times when compared to ground fines-this fact is of significance for the application of micronized particles in quasi-liquid coal-water fuel.
\end{abstract}

Keywords: coal comminution; coal micronization; hydro-jet mill; high-pressure water jet

\section{Introduction}

Until recently, hard coal has been widely used as the basic fuel in various industries. It is also the dominant fuel in the municipal power generation industry, which employs diversified technical solutions in a number of various heating systems. Specific examples of industrial uses of coal include the most energy-intensive branches of the steel and cement industries [1].

As hard coal is a non-renewable source of energy, its more environmentally friendly applications are currently being sought. However, the industrial conversion of coal is neither easy to implement nor economically beneficial. This fact is well-exemplified by the production of synthetic gasoline by using the SASOL method, which, after nearly 100 years, has become only moderately disseminated [1], and only in countries with limited economic alternatives. The case of underground (in situ) coal gasification is even less promising. Despite regular declarations from experts, such processes have not been (for safety reasons) implemented in industry-scale extraction since the early 1930s. However, efforts are still being made worldwide and in Poland [1,2] to find an effective method for carrying out such activities with the use of clean coal technologies [3] or of slurry fuels produced underground in power coal beds in order to ensure safe coal gasification processes [4].

There are also increasing efforts to use coal to produce a more ecological type of fuel. The production of coal-water slurry (CWS) fuel can be a good example of such attempts [5-7]. However, meeting such needs requires improved methods for efficient coal comminution [8-11] and for appropriate coal sorting-such that would depend on and allow for its future application [12]. 
However, considerations of various coal conversion or modification methods should be based on an in-depth knowledge of the global resources of this relatively cheap and widely available fuel [13]. Avoiding significant errors is possible only by relying on proven and accepted methods of coal sampling and testing [14], as well as on comprehensive forecasts of its energy usefulness [15]. A proper qualification of coal with a view to its appropriate technical application requires not only multi-aspect analyses of those of its characteristics which facilitate micronization, but also extensive investigations of their synergistic effect on the efficiency of the combustion process [16], and also examinations of other technological properties of this fuel [8]. Such analyses should importantly include the structure and petrography of coal, as well as its technological properties [17]. Due to the use of a high-pressure water jet and various procedures performed in a water environment, it is important to appropriately separate the particles of the pulverized coal from the excessive technological water [18].

While taking into consideration the above conditions and requirements, a thorough analysis should also be carried out on the one hand into the usefulness of the currently used industrial mining equipment [19] and its modernization potential in terms of pneumatic and especially water segregation of both coal particles [20] and fines of the smallest size [21], and on the other hand into the chemical treatment of the surface of coal particles [22]. One of the key issues in this context includes the possibility of using multistage rotary pneumatic devices [23] for the micronization of coal particles and the technology of producing nanoparticles with the use of a high-pressure water jet [24]. All of the above aspects may have a decisive influence on the future of the coal mining industry worldwide [25].

Research on an original method of coal grinding with the use of high-pressure hydrojet technologies was preceded by a meticulous analysis of all the designs of such equipment used for the comminution of brittle materials, and in particular of coal. This analysis included not only the earliest designs [26-28], which served as a basis to perform our own preliminary research [10], but also similar equipment built in China [29-32]. The analyzed subsequent designs included equipment for ultra-pure coal micronization with the use of a high-pressure water jet [33] and of coal-water slurry flowing through a labyrinthshaped comminuting channel [34]. The review also covered other coal micronization devices [6,35], as well as a test rig developed for investigating cavitation-supported hydrojet comminution of coal for the production of ultrafine coal particles [36,37], together with its technical characteristics presented in [38]. Consideration was also given to [39], which offers a detailed and comprehensive description of the methods for the fabrication and processing of various fine particles. Based on this prior knowledge and experience, an original design of a hydro-jet mill was developed [11,40].

Tests performed as part of the defined research program demonstrated the usefulness of a vibrating mill in the micronization process of two types of coal fine [7], intended for the production of CWS fuel. They also confirmed a positive effect of the comminution degree of brittle materials on the shape of their particles under mechanical grinding in an electro-hydraulic mill [41]. On the other hand, the tests showed a limited usefulness of ultrasound treatment for coal comminution in an aqueous environment [42]. Still, the usefulness of a fractal model to characterize the degree of the particle size distribution of coal [37] comminuted in a hydro-jet mill was positively evaluated.

Due to the use of high-pressure hydro-jet coal comminution technologies, research into the energy of such hydrodynamic water strokes [43-45] plays an important role in analyzing the mechanism of coal comminution [43]. This mechanism is complex and involves a number of phenomena. As the water jet hits the particles of the comminuted material, it penetrates their fracture system, causing tensile stresses to develop inside the particles [26,33]. Coal is several times less resistant to such stresses than to compressive stresses, which are dominant during the process of grinding in mechanical mills. Under the pressure of a hydraulic wedge, these fractures propagate relatively easily, causing the particles of such a material to disintegrate. Therefore, the most interesting comminution results are observed when the mechanical impact is applied simultaneously with the impact 
of a high-pressure water jet $[29,33]$, which is the case in a hydro-jet mill $[10,30,32]$. The application of a high-pressure water jet is thus advantageous in the disintegration process of brittle minerals [27], especially of hard coal [11,16], in which it induces the formation of multiple fractures $[35,43]$ adequate to its lamellar structure [17].

For these reasons, water jet methods of milling brittle materials $[29,30]$ and especially coal [31] were analyzed carefully, which has indicated a need for implementing an alternative, original technology based on a high-pressure water jet. These investigations are intended to offer a technology which would allow the production of fuel from pulverized coal in a water slurry [5] or in such low-viscosity energy liquids as methanol or oils [28].

This article discusses the usefulness of the high-pressure water jet method in the comminution of hard coal and of roto-turbulent micronization in its processing into newgeneration, coal-water, pro-ecological fuels.

\section{Mineralogical Characteristics of Hard Coal}

This research was performed for the case of hard coal. The material is a sedimentary rock of plant origin, formed mainly in the Paleozoic era from plant remains which were carbonized in the absence of oxygen. It has a black color and a dull luster. Coal rock contains $75-97 \%$ carbon, $2.5-5.5 \%$ hydrogen, $2.5-18 \%$ oxygen, as well as traces of sulfur and nitrogen and other minerals, including water $(1-8 \%)$. The calorific value of pure elemental coal is $33.2 \mathrm{MJ} / \mathrm{kg}$, and in the case of hard coal, it ranges from 16.7 to $29.3 \mathrm{MJ} / \mathrm{kg}$, depending on the ash, sulfur, and moisture content.

Until about 10 years ago, hard coal was a commonly used fuel in Poland [3], and its annual output was about 75 million metric tons. As an energy source of this type, hard coal is classified as a non-renewable source and therefore more environmentally friendly applications are currently being sought for it. One of the future directions of its application is the production of coal-water slurry (CWS)-type fuels $[5,6]$. This application requires hard coal particles to be comminuted to a substantial degree and transformed into a homogeneous water suspension. Such a fuel can be ecologically combusted, not only in power boilers [5] but also in experimental combustion engines [6], while ensuring several times lower emission levels of such harmful compounds as $\mathrm{SO}_{2}$ and $\mathrm{NO}_{\mathrm{x}}$.

The material investigated in the present study was typical fines. The particle size percentage composition of such fines is shown in Figure 1.

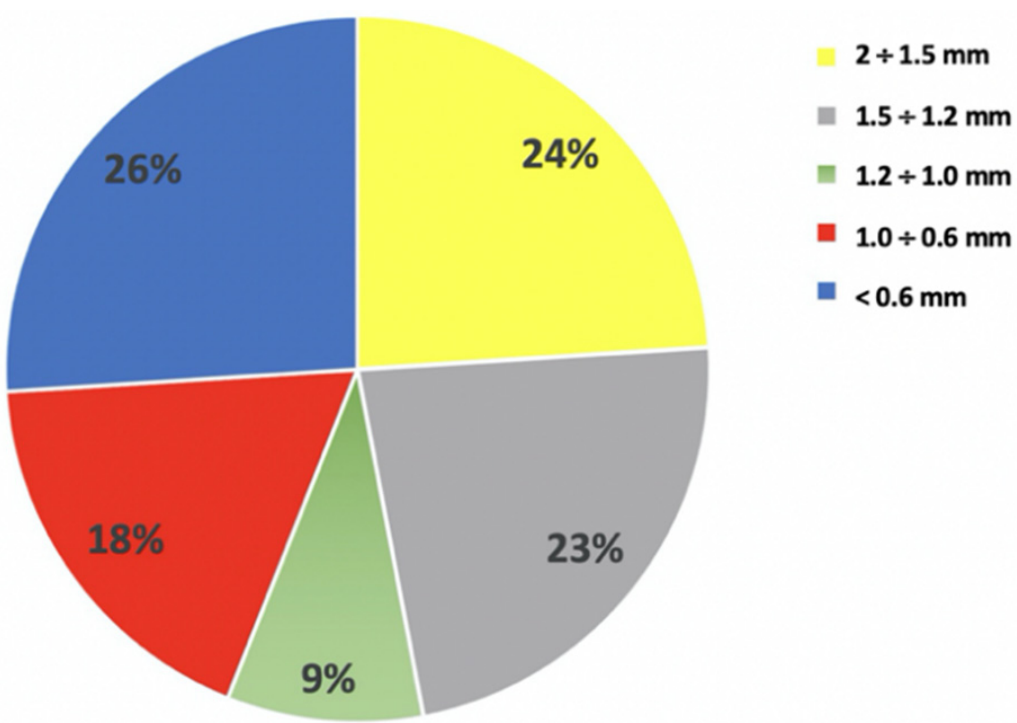

Figure 1. Particle size percentage composition of fines. 


\section{Equipment and Research Methodology}

Prior experience $[11,27,28,32]$ allowed a simulation of the functioning of the main components of the hydro-jet mill. On this basis, a vertical mill design was selected, as it offered the most advantageous operating characteristics. The design served to develop and build an original prototype of a vertical hydro-jet mill. The prototype of this mill, together with a high-pressure hydraulic monitor based on the Hammelmann HDP 164 pump, are the main units of the research installation designed for the comminution of coal (Figure 2).

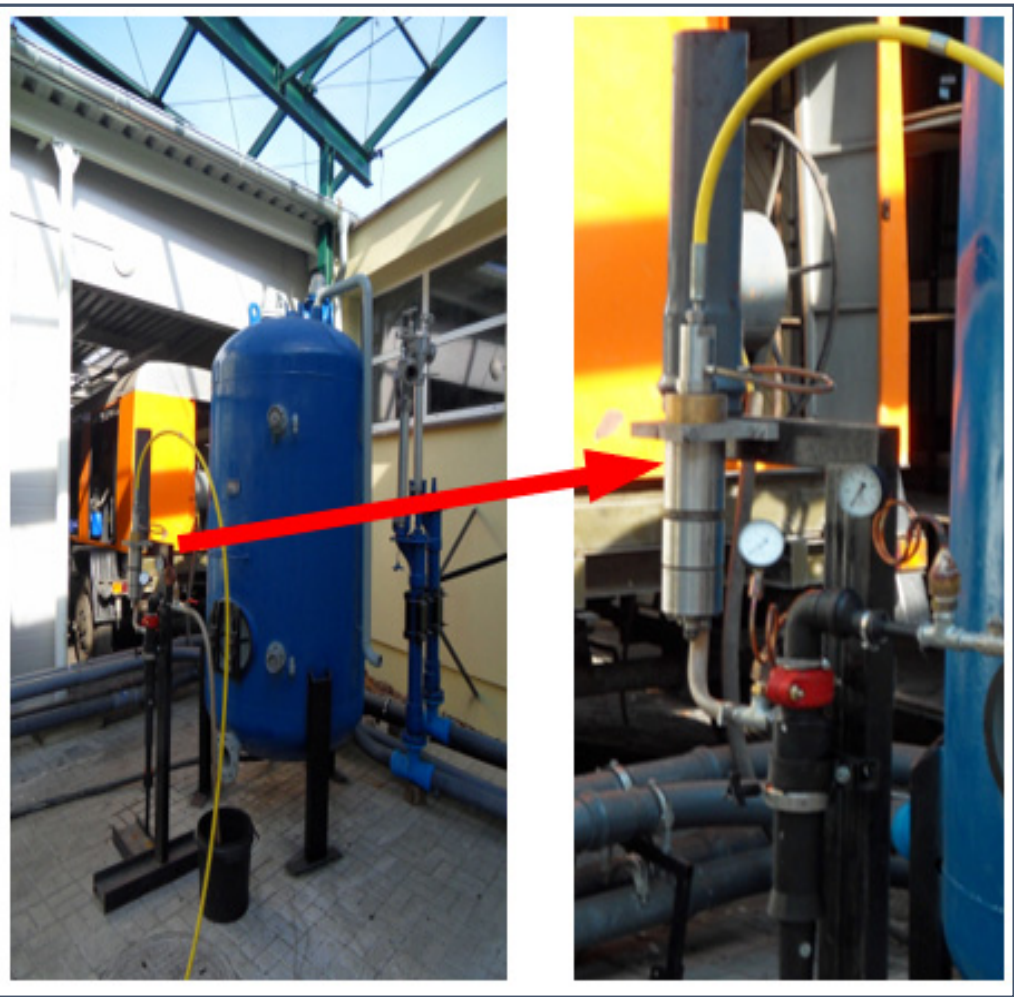

(a)

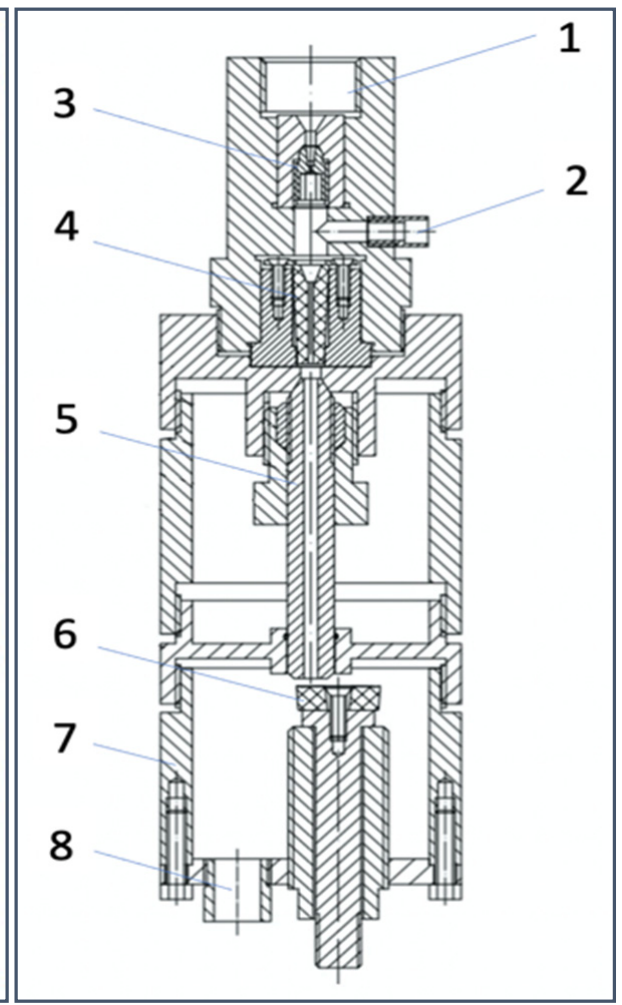

(b)

Figure 2. Vertical hydro-jet mill: (a) General view of comminuting installation; (b) Draft of a hydro-jet mill: 1-HP water inlet, 2-raw coal inlet, 3-water nozzle, 4-comminuting nozzle, 5-homogenizing nozzle, 6-comminuting disk, 7-shredding chamber, 8-coal slurry outlet.

Basic efficiency tests of hydro-jet comminuting of hard fine coals were performed under the following conditions:

- Nominal water jet pressure, $p=100,150,200$, and $250 \mathrm{MPa}$.

- Water nozzle diameter, $d_{w}=0.6,0.7,0.8,0.9$, and $1.0 \mathrm{~mm}$.

- Type and diameter of the comminuting nozzle made by Kennametal: nozzles type TL (with conical-cylindrical opening), $d_{c}=1.57,2.4$, and $3.4 \mathrm{~mm}$, and nozzle type TR, with a larger cone and a stepped opening edge having diameter, $d_{c 1}=2.4 \mathrm{~mm}$.

- Homogenizing nozzle length (with the opening diameter, $d_{h}=4.5 \mathrm{~mm}$ ), $l=100,150$, 200, and $250 \mathrm{~mm}$.

- Distance between the outlet of the homogenizing nozzle and the comminuting disc: $s=10,20,30$, and $50 \mathrm{~mm}$.

The comminution degree of hard coal particles was increased by constructing an additional technological installation (Figure 3 ) based on a roto-turbulent micronizer. A highly diluted coal suspension obtained in the previous operation (comminution) undergoes a thickening process in a block of dedicated hydro-cyclones. It is then fed to the 
micronizer (Figure 3b), in which coal particles undergo multistage micronization between three concentric circles of striking pins placed in counter-rotating rotors.

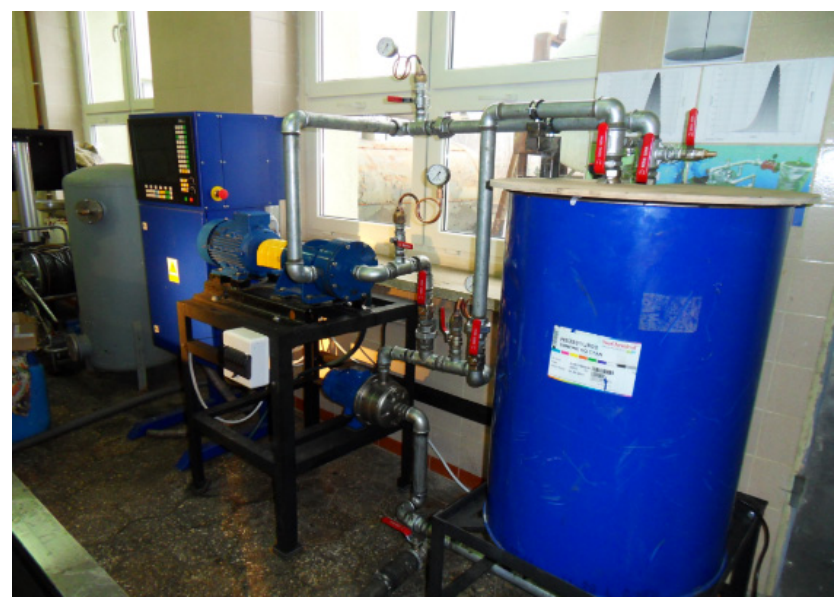

(a)

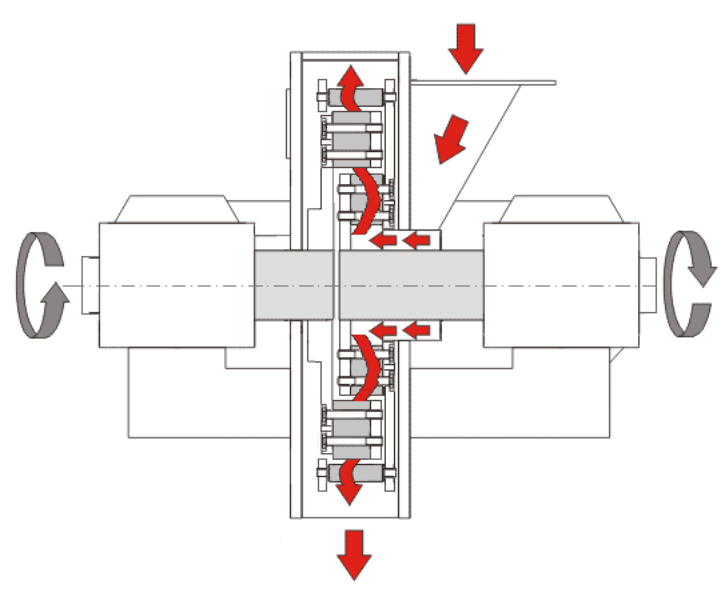

(b)

Figure 3. Roto-turbulent micronizer: (a) General view of micronizing installation; (b) Diagram of roto-turbulent micronizer.

The macro- and micro-structure of the surface of coal particles at various stages of the comminuting process were analyzed with the use of an FEI Quanta 200 Mark 2 scanning electron microscope. The effects of the comminuting of hard coal particles were measured with the Analysette 22 MicroTec Plus laser particle size meter, equipped with two semiconductor lasers providing particle size distributions in the range of $0.08-2000 \mu \mathrm{m}$. As a rule, such particle size distributions are prepared in a logarithmic order of their dimensions, as illustrated by a typical plot in Figure 4a. However, in the case of micronized coal particles, the analysis is more effective if performed on charts with a linear system of dimensions, as it allows a number of different charts to be considered simultaneously (typical example in Figure 4b).

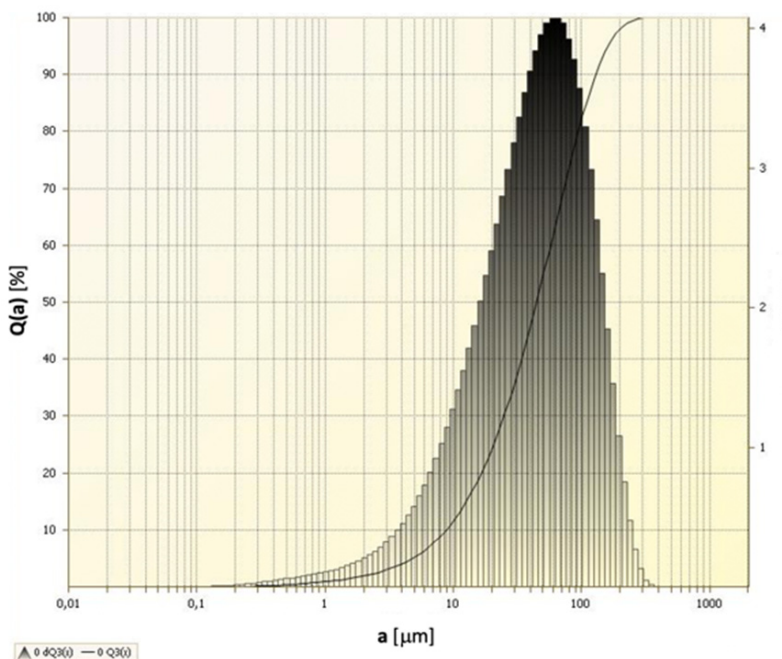

(a)

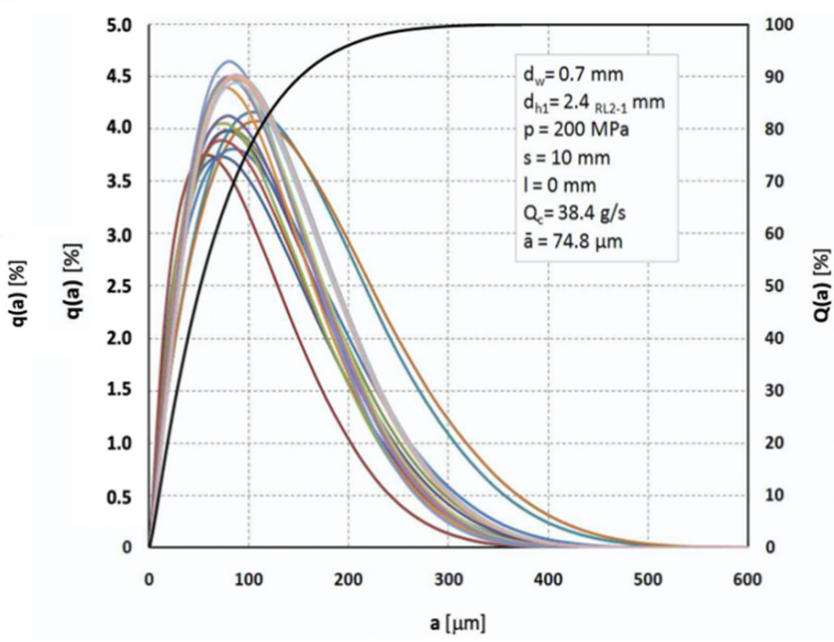

(b)

Figure 4. Illustrative distributions of hard coal particles comminuted at water pressure $p=200 \mathrm{MPa}$ : (a) typical single histogram distribution in a logarithmic scale of dimensions, and (b) comparison of 20 distributions prepared in a linear scale of dimensions. 
Twenty parallel measurements were performed for each test series. Subsequently, their histogram charts, prepared on a logarithmic scale, served to prepare a summary of the distributions of comminuted particles on a linear scale, as well as to plot the average cumulative particle quantity (up to $100 \%$ ) (Figure 4 b). In order to facilitate the graphic evaluation of the test results, one average distribution was prepared from the twenty parallel distributions. Such average distributions of the comminuted particles were used in all subsequent diagrams illustrating the test results discussed below.

\section{Hydro-Jet Comminution of Hard Coal}

The tests of the comminution of hard fine coals allowed an observation that an increase in the pressure of the water jet results in an intensified coal comminution. This phenomenon is illustrated by the average size distribution of hard coal particles comminuted in the hydro-jet mill without the homogenizing nozzle, as illustrated in Figure 5a. It shows that at the water jet pressure of $100 \mathrm{MPa}$, the average size of the comminuted hard coal particles is about $\bar{a}=117 \mu \mathrm{m}$, at $150 \mathrm{MPa}$ the size of such particles is $\bar{a}=85.2 \mu \mathrm{m}$, for $p=200 \mathrm{MPa}$ it is $\bar{a}=74.8 \mu \mathrm{m}$, while for the maximum pressure $(250 \mathrm{MPa})$, the size reaches $\bar{a}=60.5 \mu \mathrm{m}$.

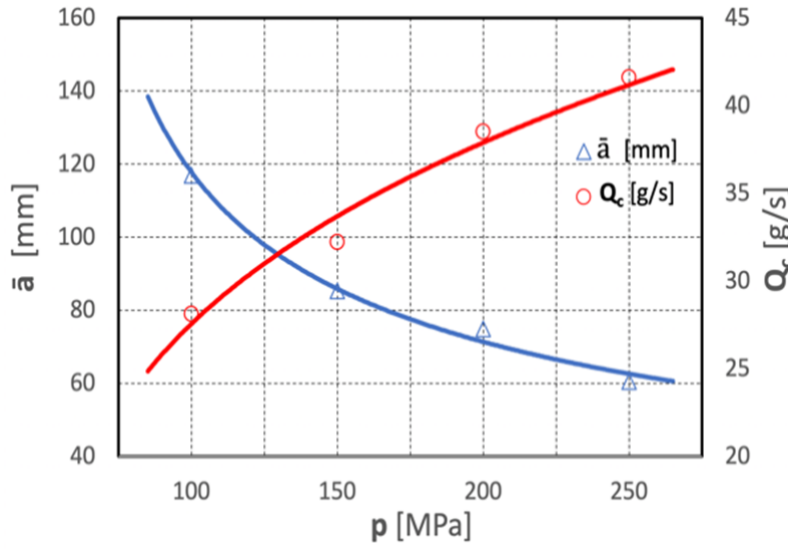

(a)

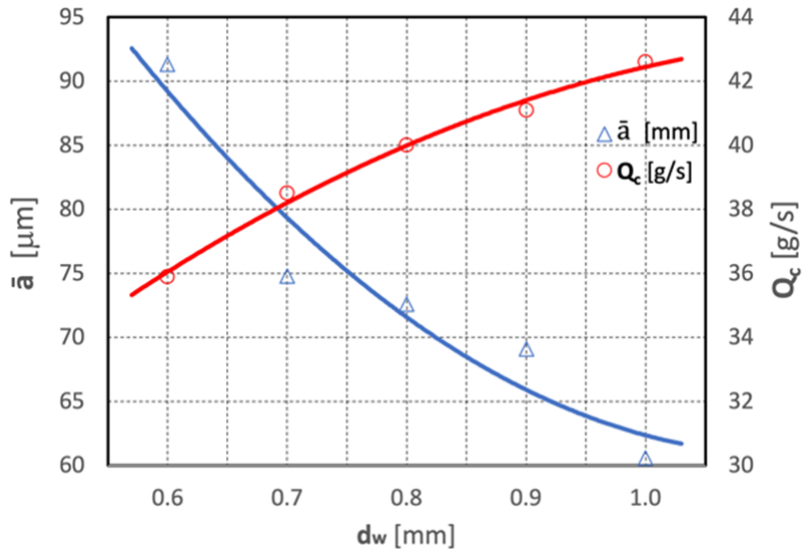

(b)

Figure 5. Effectiveness of the comminution process and efficiency of hydro-jet milling for hard coal in relation to: (a) pressure, at water nozzle diameter $d_{w}=0.7 \mathrm{~mm}$, and (b) water nozzle diameter, at $p=200 \mathrm{MPa}$. Common test conditions: $d_{c 1}=2.4 \mathrm{~mm}$, $s=10 \mathrm{~mm}$.

Similarly, increasing the diameter of the water jet also has a positive effect on the comminution degree of hard coal particles. An example of this phenomenon is presented in Figure $5 b$, which shows a set of averaged size distributions of hard coal particles comminuted in the hydro-jet mill at $200 \mathrm{MPa}$. With the water nozzle diameter of $0.6 \mathrm{~mm}$, the average size of the comminuted hard coal particles is $\bar{a}=91.3 \mu \mathrm{m}$, for the nozzle diameter of $0.7 \mathrm{~mm}$, the average is limited to $\bar{a}=74.8 \mu \mathrm{m}$, for the nozzle diameter $d_{w}=0.8 \mathrm{~mm}$, the average is $\bar{a}=72.6 \mu \mathrm{m}$, for $d_{w}=0.9 \mathrm{~mm}$, the average is $\bar{a}=69.1 \mu \mathrm{m}$, and for $d_{w}=1.0 \mathrm{~mm}$, the particle size is the smallest $(\bar{a}=60.6 \mu \mathrm{m})$.

After analyzing all of the test results and considering most of the relevant evaluation criteria, the water nozzle with $d_{w}=0.7 \mathrm{~mm}$ was selected, as it allows the most effective coal comminution. This choice was confirmed by analyses of both the efficiency of the coal milling process and of the optimal values of specific energy consumption of this process.

The comminuting nozzle diameter has an opposite effect. An increase in the diameter of the TL-type nozzle results in a decrease in the degree of hard coal comminution. On the other hand, the greatest effectiveness was obtained with the use of a TR-type comminuting nozzle with a stepped opening edge, which intensifies the comminution process. For the above reasons, the TR-type nozzle was used in all of the subsequent tests.

The use of a homogenizing nozzle is important for the efficiency of hard coal comminution. This observation applies to the type of the opening in such a nozzle, and in 
particular to its length. Figure 6 shows illustrative results obtained with the use of such a nozzle with an opening diameter of $d_{h}=4.5 \mathrm{~mm}$. The upper graph illustrates the results of comminution of fines using a homogenizing nozzle with a smooth opening, and the lower graph was obtained for the bore with grooves in the form of coarse threads, similar to those used in the barrels of pneumatic weapons. This diagram shows that the highest degree of coal comminution is obtained with the use of such a nozzle, having a length of approximately $200 \mathrm{~mm}$. Importantly, the use of nozzles with threaded grooves in the opening results in coal particles being $7-12 \%$ finer than in the case when nozzles with a smooth opening are used.

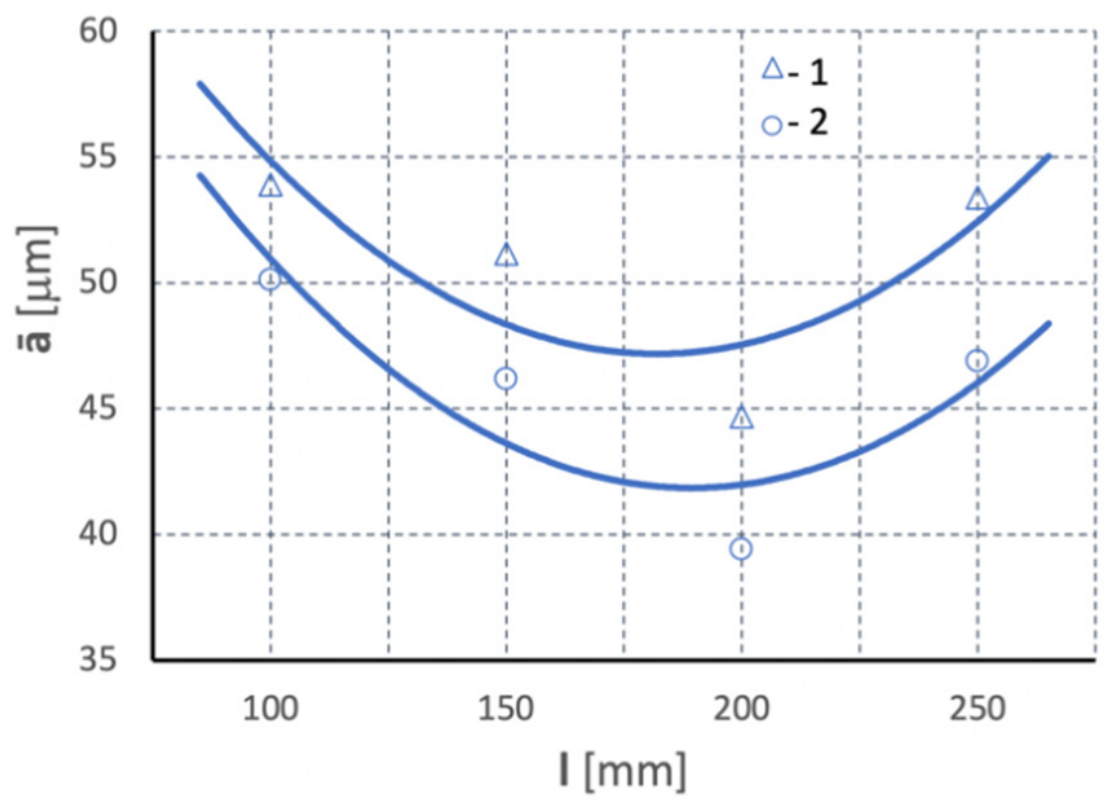

Figure 6. The average particle size of comminuted hard coal $(\bar{a})$ in the function of the length (l) of the homogenizing nozzle without the thread-groove opening (1) and with the thread-groove opening $d_{h}=4.5 \mathrm{~mm}(2)$.

As can be seen from the above tests, the optimum length of the homogenizing nozzle is $190 \mathrm{~mm}$. Therefore, a homogenizing nozzle of this length was used in all of the subsequent tests.

\section{Results and Discussion}

Considering the use of a homogenization nozzle with an optimized length of $l=190 \mathrm{~mm}$ in the hydro-jet mill, example results are shown in Figure 7. It shows illustrative results of tests on how the efficiency of hard coal comminution is influenced by the distance from the homogenizing nozzle outlet to the comminuting disk.

The tests clearly show that the distance from the homogenizing nozzle outlet to the comminuting disk is an important geometrical parameter determining the efficiency of hard coal comminution in such a hydro-jet mill. For the above reasons, the smallest technically possible distance, $s=10 \mathrm{~mm}$, is the most advantageous solution, and it was used in all of the subsequent tests. Analogous effects were obtained in [44] performed with the use of slightly different technological equipment.

An example of such results can be presented in diagrams of averaged size distributions of hard coal particles comminuted in a hydro-jet mill equipped with a homogenizing nozzle, having a length $l=190 \mathrm{~mm}$, at various water pressure values (Figure 8a). The diagrams served as a basis to conclude that in such comminution conditions, at the water jet pressure of $100 \mathrm{MPa}$, the average size of the comminuted hard coal particles is approximately $\bar{a}=105.2 \mu \mathrm{m}$, at the water pressure of $150 \mathrm{MPa}$, the size of such particles is $\bar{a}=57.8 \mu \mathrm{m}$, 
for $p=200 \mathrm{MPa}$, it is $\bar{a}=39.4 \mu \mathrm{m}$, while for the maximum pressure of $250 \mathrm{MPa}$, the size reaches $\bar{a}=31.8 \mu \mathrm{m}$.

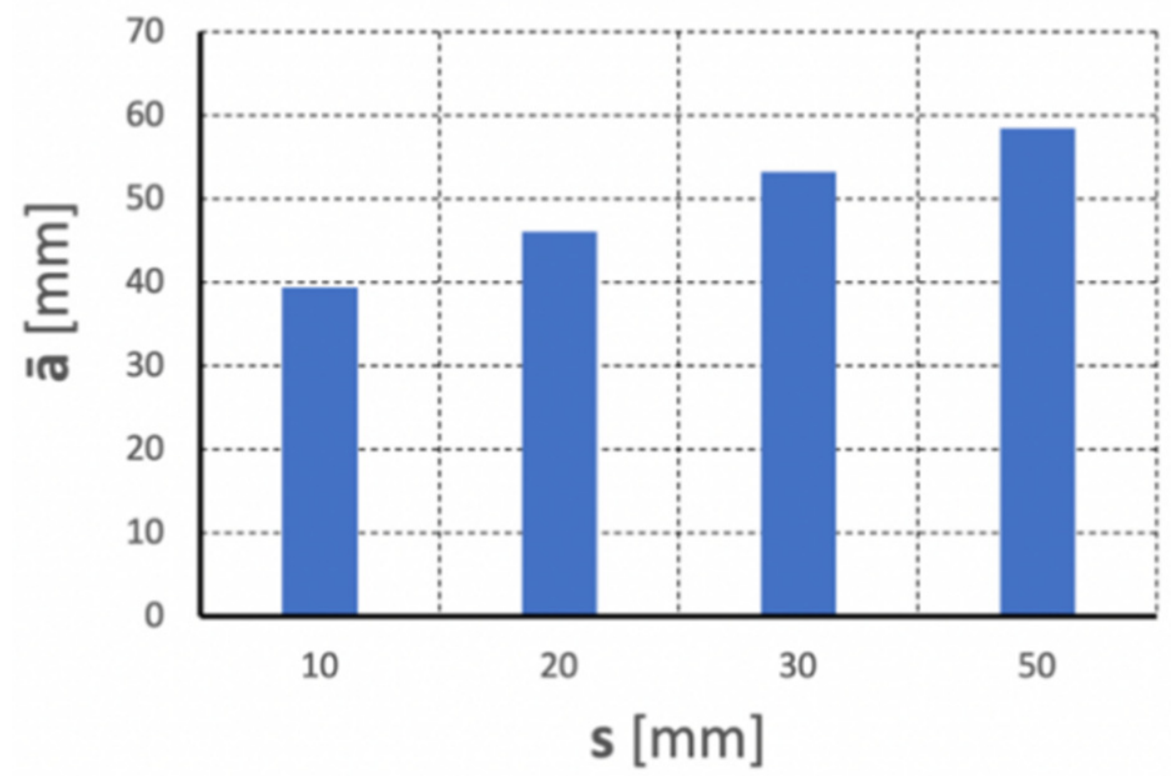

Figure 7. Influence of distance, $s$, from the homogenizing nozzle outlet to the comminuting disk on coal comminution efficiency. Test conditions: $p=200 \mathrm{MPa}, d_{w}=0.7 \mathrm{~mm}, d_{c 1}=2.4 \mathrm{~mm}, d_{h}=4.5 \mathrm{~mm}$, $l=190 \mathrm{~mm}$.

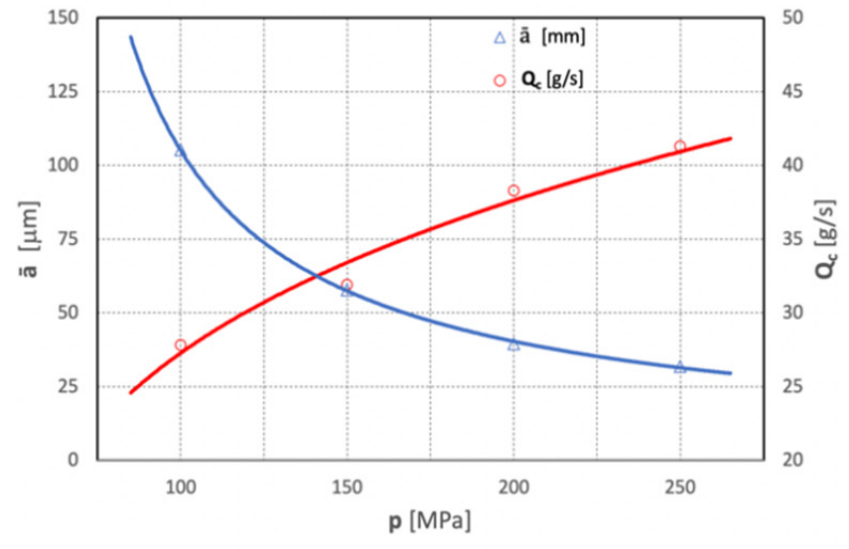

(a)

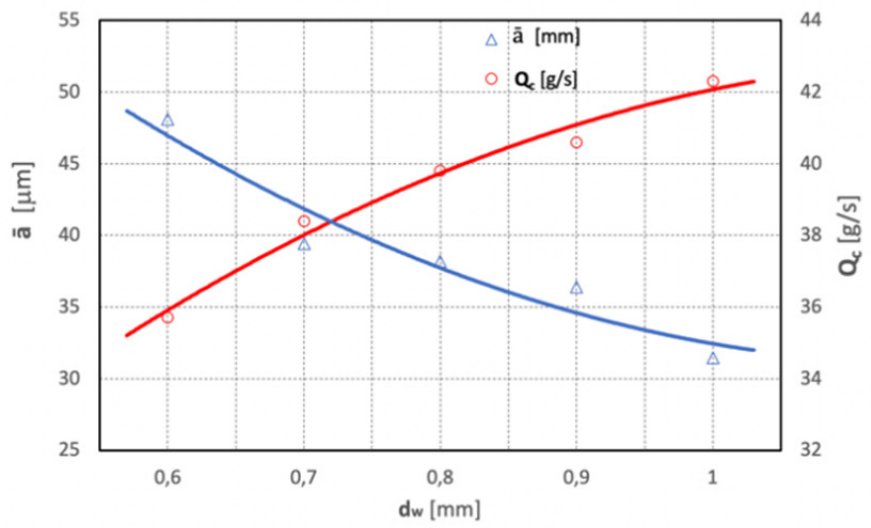

(b)

Figure 8. Effectiveness of the comminution process and efficiency of hydro-jet milling for hard coal in relation to: (a) pressure, at water nozzle diameter $d_{w}=0.7 \mathrm{~mm}$, and (b) water nozzle diameter, at $p=200 \mathrm{MPa}$. Common test conditions: $d_{c 1}=2.4 \mathrm{~mm}, l=190 \mathrm{~mm}, s=10 \mathrm{~mm}$.

As indicated by the graphs in Figure 8a, particle sizes obtained using a hydro-jet mill equipped with a homogenizing nozzle having length $l=190 \mathrm{~mm}$ are much finer than the particle sizes obtained in a mill without this nozzle. For example, if the effectiveness of the comminution shown in Figure 8a is compared with earlier results (Figure 5a), depending on the test conditions, the degree of coal comminution in a hydro-jet mill equipped with a homogenizing nozzle is from $11 \%$ to $47 \%$ more favorable.

As illustrated by the above diagrams, an increase in water jet pressure has a positive effect on the coal comminution efficiency, measured by the average size of the obtained particles. Increasing the water jet pressure also increases the efficiency of the hydro-jet comminuting process, as illustrated in Figure 8a. This phenomenon is due to an increase 
in both the water flow and in the velocity of the comminuted coal particles, which causes an increase in their energy. At the pressure of $100 \mathrm{MPa}$, the efficiency of the hydro-jet comminution process is approximately $27.8 \mathrm{~g} / \mathrm{s}$, for the pressure of $150 \mathrm{MPa}$, the efficiency is $31.9 \mathrm{~g} / \mathrm{s}$, and for $p=200 \mathrm{MPa}$, it is $38.4 \mathrm{~g} / \mathrm{s}$, while at the maximum water pressure (250 MPa), the efficiency increases to $41.3 \mathrm{~g} / \mathrm{s}$.

Similar effects are also obtained by increasing the diameter of the water nozzle. This manipulation also results in an increase of the water flow rate, contributing to the improvement of hard coal comminution mechanisms, and thus, in an increase of the comminution efficiency. This fact is confirmed by specific dependences between the increase in the comminution efficiency and the water nozzle opening diameter, as presented in Figure 8b. For example, for a water nozzle with a diameter of $0.6 \mathrm{~mm}$, the efficiency is $35.7 \mathrm{~g} / \mathrm{s}$, while for the diameter $d_{w}=0.7 \mathrm{~mm}$, it is equal to $38.4 \mathrm{~g} / \mathrm{s}$. With the nozzle diameter further increased to $0.8 \mathrm{~mm}$, the comminution process efficiency is increased to $39.8 \mathrm{~g} / \mathrm{s}$, and in the case of a nozzle of $0.9 \mathrm{~mm}$ in diameter, the average process efficiency is $40.6 \mathrm{~g} / \mathrm{s}$. The maximum diameter of the water nozzle used, equal to $1.0 \mathrm{~mm}$, allows a comminution efficiency of $42.3 \mathrm{~g} / \mathrm{s}$. A similar influence of the water nozzle diameter was also observed in a study [38] performed using different technological equipment.

In the search for more effective ways of coal comminution, attention must be paid to the evaluation of energy expenditures incurred in such processes. Specific energy consumption for the comminution of fines in a hydro-jet mill can be determined from the following equation:

$$
E_{H} \cong \frac{p \cdot Q_{w}}{Q_{c}}
$$

Figure 9 shows an example of such a relationship between specific energy consumption in the hydro-jet coal comminution method and water pressure. Figure 9a, on the other hand, illustrates the effect of water pressure on specific energy consumption in the comminution process of fines. An increase of the water pressure in a hydro-jet mill from 100 to $250 \mathrm{MPa}$ causes a nearly 3 -fold increase of the energy consumption, and also a nearly 1.6-fold increase of the water flow rate. Similar dependencies are observed when the diameter of the water nozzle is increased from 0.6 to $1 \mathrm{~mm}$ (Figure 9b), in which case the water flow rate increased nearly 2.8 -fold.

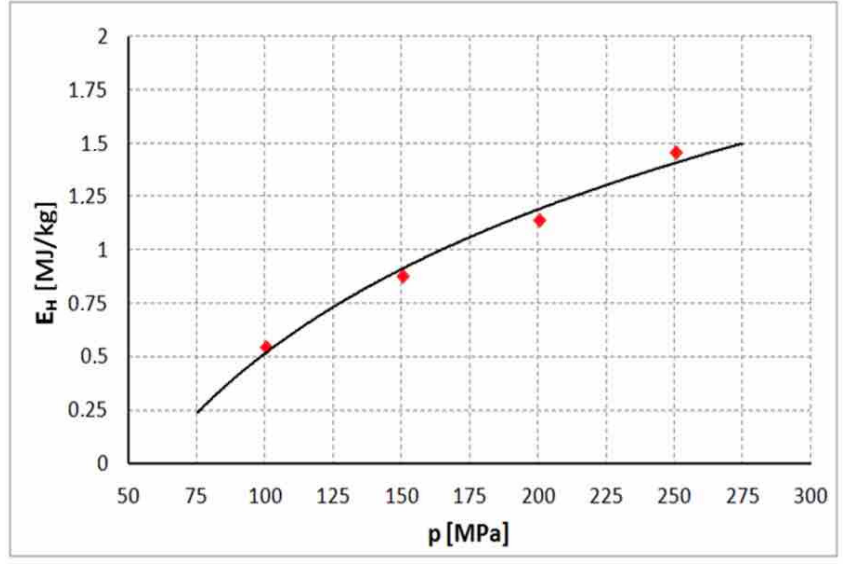

(a)

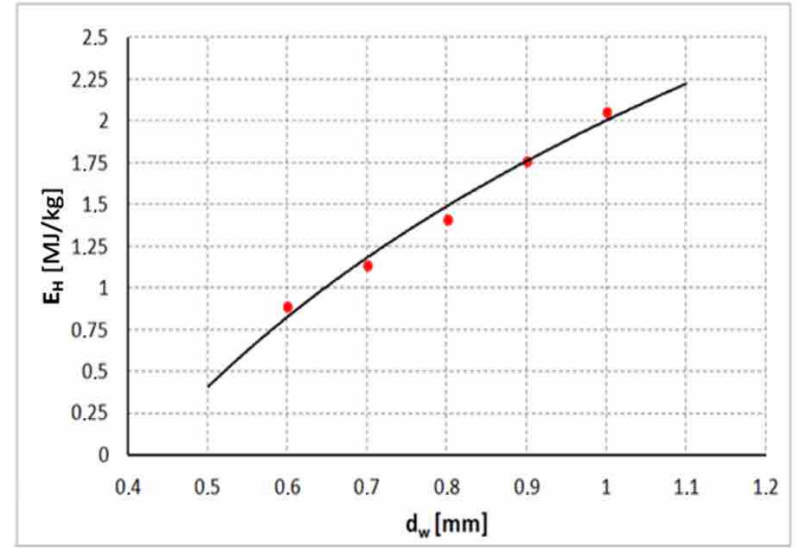

(b)

Figure 9. Specific energy consumption of the hard coal comminution process in a hydro-jet mill in relation to: (a) pressure, at water nozzle diameter $d_{w}=0.7 \mathrm{~mm}$, and $(\mathbf{b})$ water nozzle diameter, at $p=200 \mathrm{MPa}$. Common test conditions: $d_{c 1}=2.4 \mathrm{~mm}$, $l=190 \mathrm{~mm}, \mathrm{~s}=10 \mathrm{~mm}$. 
In the case of a planetary ball-mill, type PM 100, the energy expenditure incurred in coal comminution is calculated differently. Such specific energy consumption of fines grinding is described by the following equation:

$$
E_{M}=\frac{P}{Q_{c}}=\frac{P \cdot t}{m_{c}}
$$

When analyzing the results of earlier research works performed, following different methods, on energy consumption in the comminution processes of various brittle materials [10,40], including hard coal [11], the energy consumption of hydro-jet comminution of such materials was identified to be significantly lower than the energy consumption in the case of mechanical grinding, e.g., in a planetary ball-mill. In order to objectively evaluate such dependencies, an index was thus used which describes the multiplier of benefits resulting from the reduced energy consumption in the process of hydro-jet coal comminution. The index is calculated according to the following relationship:

$$
W_{K}=\frac{E_{M}}{E_{H}}
$$

The benefit multiplier thus calculated for the different types of the tested materials, ground to such a degree that the average particle size is in the range $\bar{a}=30.2-37.7 \mu \mathrm{m}$, is best illustrated in the graph of Figure 10.

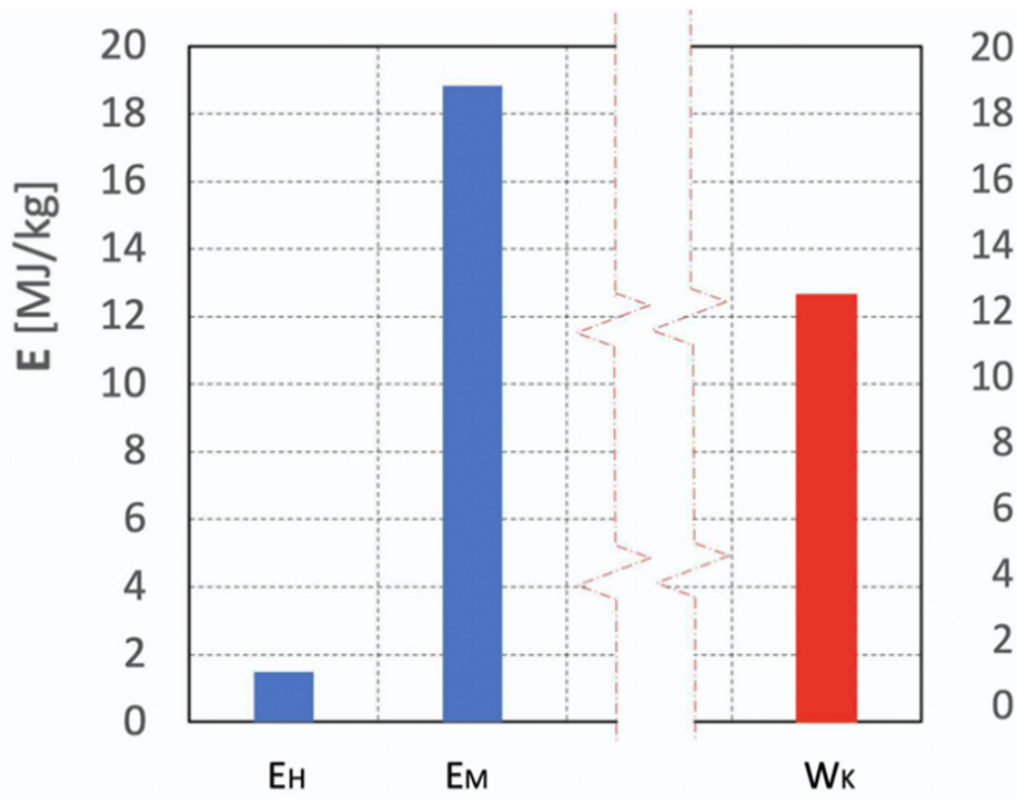

Figure 10. Specific energy consumption of hard coal comminution to the level of $\bar{a}=35.9 \mu \mathrm{m}$ performed in a hydro-jet mill $\left(E_{H}\right)$ and ground in a planetary ball-mill, type PM $100\left(E_{M}\right)$, together with the benefit index $\left(W_{K}\right)$.

Such relationships are understandable, as the application of a high-pressure water jet in hard coal comminution is particularly effective. This effectiveness results from the fact that such dynamic conditions lead to the formation of a system of structural fractures in hard coal $[29,33,35]$ wedged by water, which easily opens their lamellar structure [17] due to the relatively low strength of coal to tensile stresses $[10,11,29,33]$ which occur under such conditions. As a result, the energy consumption of the coal comminution process in the hydro-jet mill is more than 12 -fold lower than in the case of grinding in a mechanical planetary ball-mill.

The morphology of coal particle surfaces is very important for the effectiveness of the comminution process, especially in the case of producing coal-water fuel. A decrease in 
the grain size of the obtained coal particles causes their specific surface area to increase, especially when, under the influence of the hydrodynamic impact, a system of structural fractures is formed on their surfaces. Microscopic examination of the comminuted coal particles indicates that when these fractures are penetrated by a high-pressure water jet, the particle surfaces typically develop jagged lamellae. This phenomenon intensifies their combustion process, being a factor decisive for the efficiency and power of a boiler unit.

Figure 11 shows examples of the morphology of such hard coal particles, which are the main components of the new type of coal-water fuel.

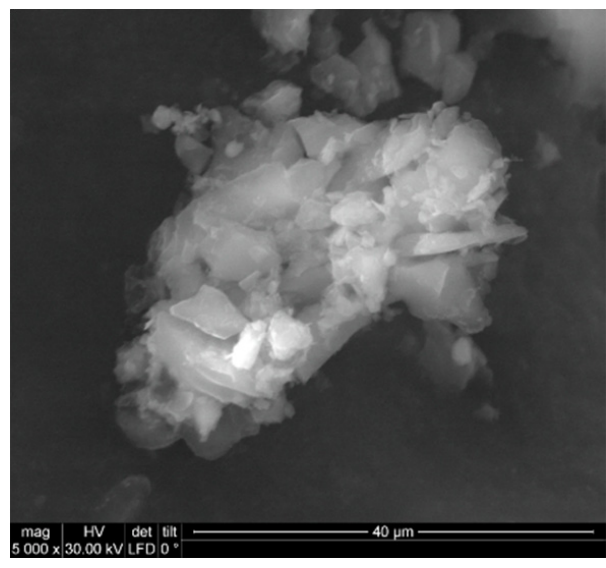

(a)

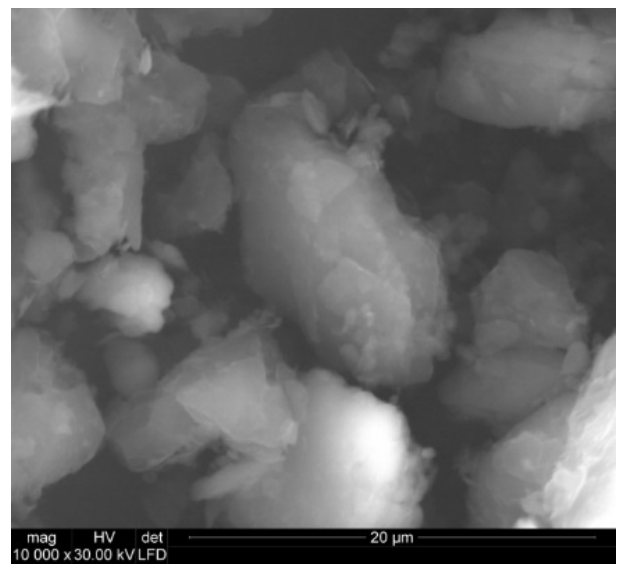

(b)

Figure 11. Examples of SEM images of hard coal particles comminuted in a hydro-jet mill at a water jet pressure of $200 \mathrm{MPa}$ : (a) Conglomerate of comminuted superfine coal particles showing out their structures; (b) multi-particle view of comminuted coal.

However, it should be kept in mind that in order to minimize the sedimentation of coal particles in an aqueous suspension, an even more significant increase in the degree of their comminution is required, down to $\bar{a}<20 \mu \mathrm{m}[10,11]$.

\section{Roto-Turbulent Micronization of Hard Coal}

The more intensive the comminution of coal, the higher the efficiency of the coal combustion process. The comminution degree of hard coal particles was increased by constructing an additional technological installation, which was based on a roto-turbulent micronizer. Closer details of this solution are included in the description of Figure 3 above.

In order to thicken a relatively thin suspension of coal particles comminuted in the hydro-jet mill, it is dewatered with the use of specially designed hydro-cyclones. Moreover, impurities are removed from such suspensions and stabilizing additives are introduced instead. A more intensive micronization of coal particles was obtained by using a rototurbulent micronizer at this stage. This device also allows the homogenization of such water-coal pulp, limiting the sedimentation phenomenon of coal microparticles. Figure 12 shows examples of the effects of the comminution operations in the hydro-jet mill and the subsequent micronization operations using a roto-turbulent micronizer.

In this figure, the results of comminuting hard coal particles in the hydro-jet mill are shown in blue. The intersection of the screening cumulative curve, which corresponds to this graph, with the indicated line $Q(a)=50 \%$, occurs at the point illustrating the average size of the comminuted hard coal particles, which is $\bar{a}=39.4 \mu \mathrm{m}$. The red color indicates the micronization plot of hard coal particles obtained after a single passing of the watercoal pulp through the roto-turbulent micronizer. The intersection point of the screening cumulative curve, which corresponds to this graph, with the indicated line $Q(a)=50 \%$, shows that the average particle size of the comminuted hard coal for such case is only $\bar{a}=17.0 \mu \mathrm{m}$. As can be seen, such a comminution degree of hard coal particles satisfies the condition of the limit size $\bar{a}<20 \mu \mathrm{m}$. A similar analysis performed for a ten-fold 
micronization process, represented by the green line in the graph, shows that under such conditions, the average particle size of the comminuted hard coal is only $\bar{a}=12.2 \mu \mathrm{m}$. Obviously, after comminuting coal in a hydro-jet mill, an optimal technological solution is to apply a single micronization procedure in a roto-turbulent micronizer, which is much cheaper than the micronisation procedure with ten repetitions.

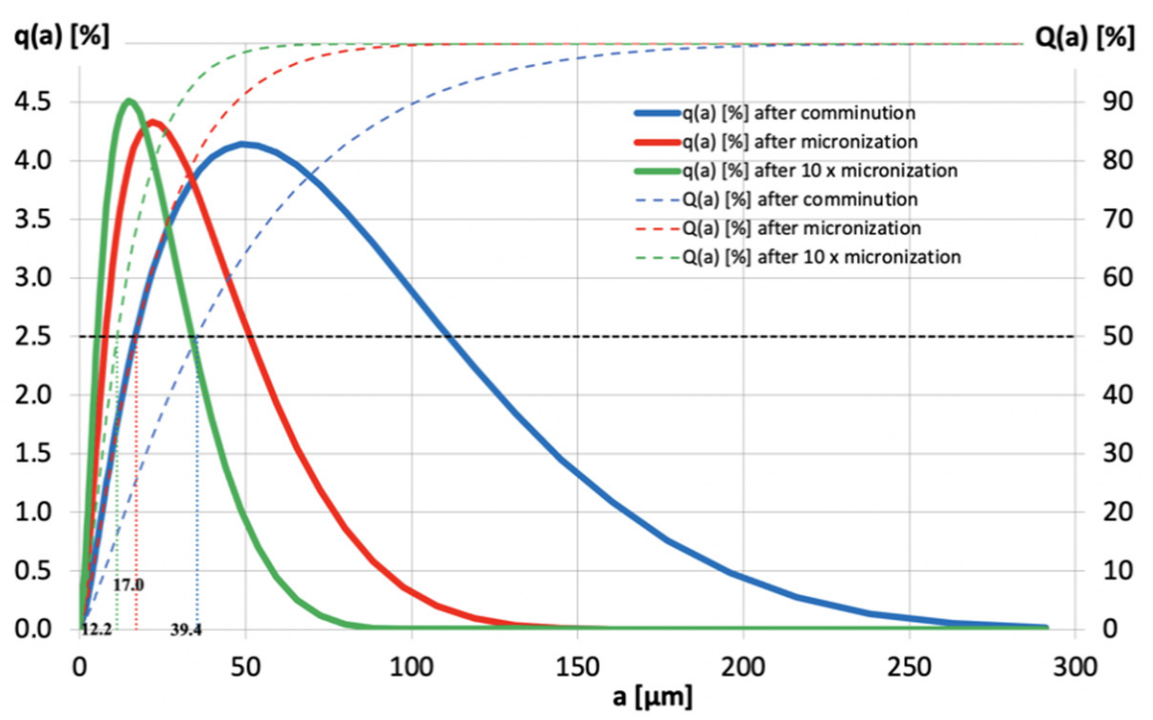

Figure 12. Particle size distributions of hard coal after comminution in a hydro-jet mill and micronization performed in a roto-turbulent micronizer.

In these types of hard coal particles, the most important factors are their grain size and surface morphology. Both characteristics can translate into an increase in the specific surface area of these particles, which in turn translates into a more intensive combustion process. Microscopic observations show that the hydro-jet micronization of coal causes specific formations to develop on the surfaces of the particles. These surfaces frequently assume the form of jagged lamellae, which significantly increase their total active surface area.

Figure 13 shows examples of the morphology of such particles produced for the purpose of the new type of coal-water fuel.

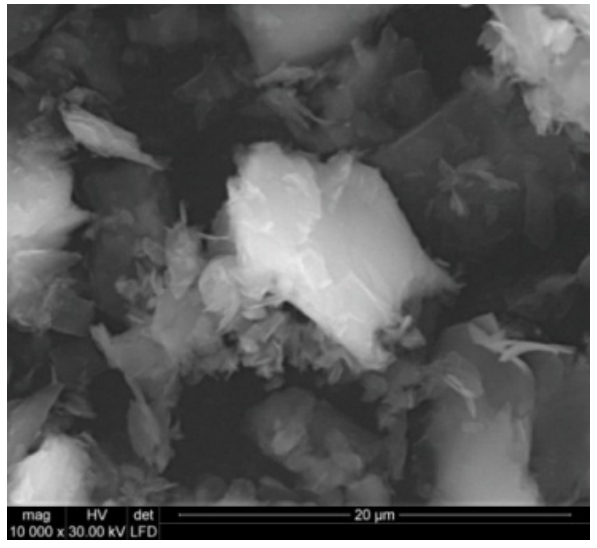

(a)

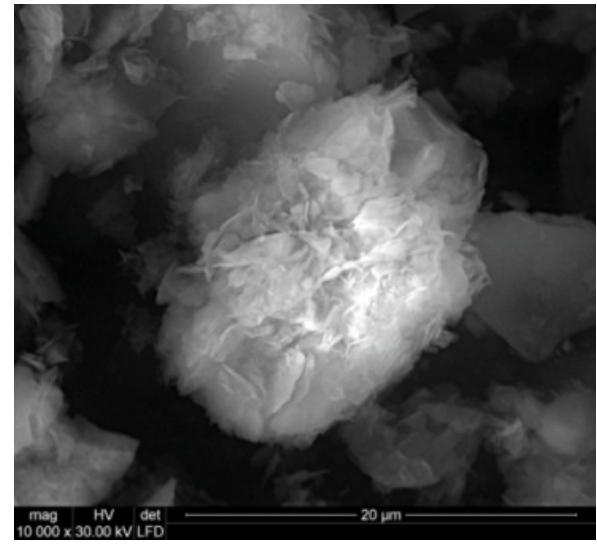

(b)

Figure 13. Examples of SEM images of micronized hard coal particles with different degrees of surface development: (a) General view of comminuted coal particles; (b) individual coal particle showing out its lamellar structure. 
Estimated results of a simulation for the lamellar morphology of coal particles formed during the high-pressure water jet comminution demonstrate that their actual surface area increases by 10,000-30,000 times. In special cases, this surface area even increases several times more, compared to the specific surface area of the particles of ordinary fines used in hydro-jet comminution. This fact demonstrates the potentially significant possibilities for intensifying the combustion efficiency of such a new coal-water fuel.

\section{Conclusions}

The developed and tested hydro-jet mill offers effective comminution of coal in the pressure range of $100-250 \mathrm{MPa}$ at a variable water flow rate in the range of $0.2-0.5 \mathrm{dm}^{3} / \mathrm{s}$. The device allows the comminution of standard fines, with a grain size up to $2 \mathrm{~mm}$ and at a relatively high efficiency of 8 to $55 \mathrm{~g} / \mathrm{s}$. Increasing the pressure of the water jet and the diameter of the water nozzle has a favorable effect on the process of hydro-jet hard coal comminution. However, it also nearly proportionally increases the energy consumption of the comminution process and the technological water consumption. Based on the results of multi-criteria analyses, the optimum conditions for hard coal comminution $(\bar{a}=39.4 \mu \mathrm{m}$, $Q_{c}=38.4 \mathrm{~g} / \mathrm{s}, E_{H}=1.1 \mathrm{MJ} / \mathrm{kg}$ ) were found to exist for the following parameters of the comminuting process and of the hydro-jet mill design:

- Water jet pressure, $p=200 \mathrm{MPa}$.

- Water nozzle diameter, $d_{w}=0.7 \mathrm{~mm}$.

- Diameter of the comminuting nozzle type, TR: $d_{c 1}=2.4 \mathrm{~mm}$.

- Diameter of the homogenizing nozzle, $d_{h}=4.5 \mathrm{~mm}$, and its length, $l=190 \mathrm{~mm}$.

- Distance of the homogenizing nozzle outlet from the comminuting disc: $s=10 \mathrm{~mm}$.

The use of a high-pressure water jet in the process of hard coal comminution is particularly effective, as this effectiveness results from the fact that such dynamic conditions lead to the formation of a system of structural fractures in hard coal wedged by water, which easily opens their lamellar structure due to the relatively low strength of coal to tensile stresses which occur under such conditions. As a result, the energy consumption of the coal comminution process in the hydro-jet mill is more than 12-fold lower than in the case of grinding in a mechanical planetary ball-mill. Moreover, the actual surface area of such particles increases 10,000-30,000 times in comparison to the specific surface area of the particles of normal fines used in hydro-jet comminution. This fact demonstrates the potentially significant possibilities for intensifying the combustion efficiency of a coal-water fuel subjected to such comminution.

On the other hand, the application of hydro-cyclone dewatering procedures to the obtained coal slurry ensures that it is considerably thickened, thus enabling an intensification of the comminution degree of coal particles in a roto-turbulent micronizer. Coal particles in such a micronizer are subjected to multistage micronization between three concentric circles of striking pins placed in counter-rotating rotors. Under such conditions, the average particle size of the comminuted hard coal is only $\bar{a}=17.0 \mu \mathrm{m}$, and this being already after the first micronization cycle. As a result, the condition of the limit size of the micronized coal particles at the level below $20 \mu \mathrm{m}$ is satisfied, thus ensuring their effective use in quasi-liquid coal-water fuel.

Author Contributions: Conceptualization, P.J.B.; methodology, P.J.B.; validation, P.J.B. and W.S.-B.; formal analysis, P.J.B. and W.S.-B.; investigation, P.J.B.; resources, P.J.B.; data curation, P.J.B. and W.S.-B.; writing — original draft preparation, P.J.B.; writing—review and editing, P.J.B.; visualization, P.J.B. and W.S.-B.; supervision, P.J.B.; project administration, P.J.B.; funding acquisition, P.J.B. All authors have read and agreed to the published version of the manuscript.

Funding: This research received no external funding.

Conflicts of Interest: The authors declare no conflict of interest. 


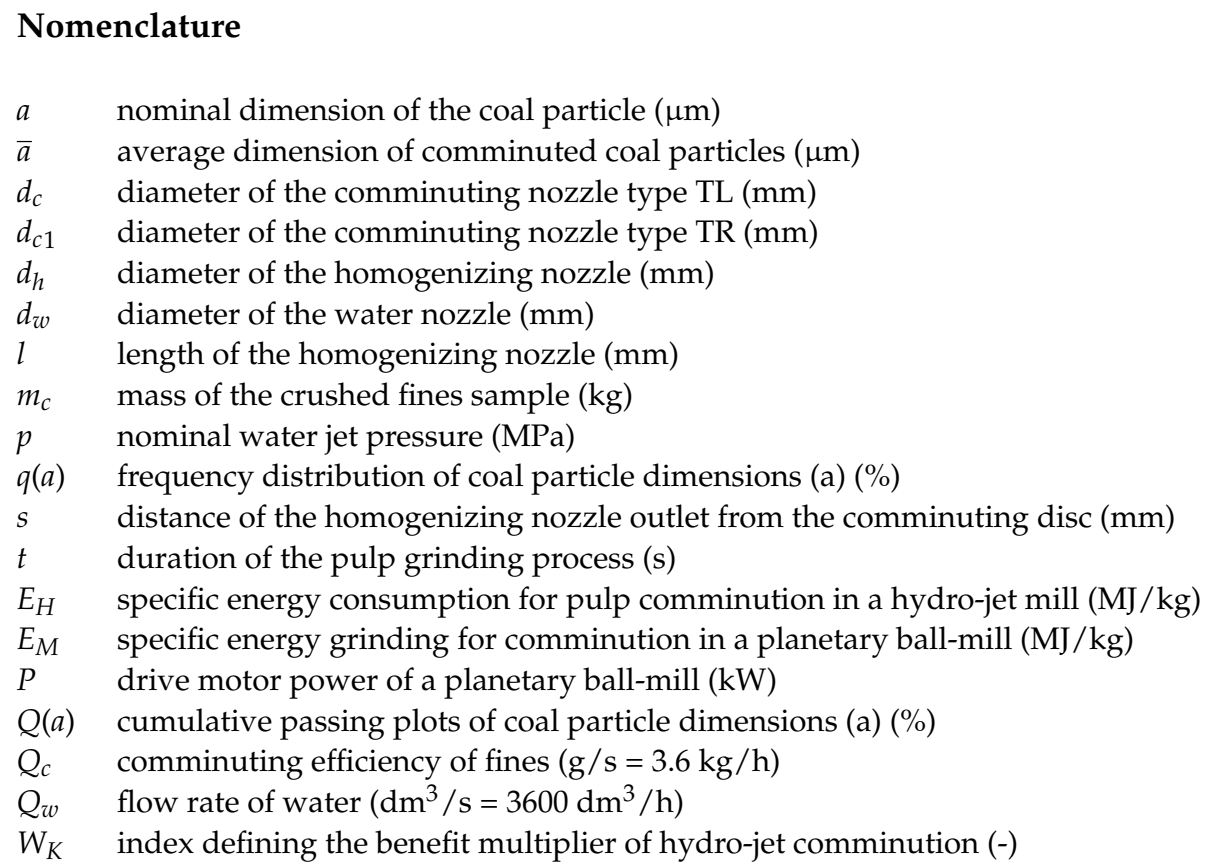

\section{References}

1. Osborne, D.G.; Gupta, S.K. Industrial uses of coal. In The Coal Handbook. Towards Cleaner Production Vol. 1: Coal Production; Woodhead Publishing Limited: Cambridge, UK, 2013; pp. 3-30. [CrossRef]

2. Lavis, S.; Courtney, R.; Mostade, M. Underground coal gasification. In The Coal Handbook. Towards Cleaner Production Vol. 1: Coal Production; Woodhead Publishing Limited: Cambridge, UK, 2013; pp. 226-239. [CrossRef]

3. Klank, M. Perspectives for coal utilization in Poland in the aspect of clean coal technologies. Econ. Miner. Raw Mater. 2007, 23, 27-33. (In Polish)

4. Robak, J.; Ignasiak, K.; Muzyka, R. Slurry fuel made from Polish energy coals to be used in the gasification process. Min. Rev. 2013, 7, 61-66. (In Polish)

5. Coal Water Slurry Technology; Tangshan Keyuan Environmental Protection Technology \& Equipment Co. Ltd.: Tangshan, China, 2003.

6. Davis, J.P. Micronized Coal-Water Fuel Slurry for Reciprocating Combustion Engines. U.S. Patent 4,335,684, 22 June 1982.

7. Robak, J.; Ignasiak, K.; Rejdak, M. Coal micronization studies in vibrating mill in terms of coal water slurry (cws) fuel preparation. J. Ecol. Eng. 2017, 18, 111-118. [CrossRef]

8. Arnold, B.J. Coal formation. In The Coal Handbook. Towards Cleaner Production Vol. 1: Coal Production; Woodhead Publishing Limited: Cambridge, UK, 2013; pp. 31-52. [CrossRef]

9. LLanes, M. Coal Comminution Using High Pressure Waterjet. Ph.D. Thesis, Colorado School of Mines, Golden, CO, USA, 1993.

10. Borkowski, P.; Borkowski, J.; Bielecki, M. Coal disintegration using high pressure water jet. Tech. Gaz. 2012, 19, 367-372.

11. Borkowski, P.; Borkowski, J.; Bielecki, M. Technical aspects of coal disintegration using high pressure water jet. J. Mechine Eng. 2012, 12, 7-19.

12. Eisele, T.C.; Walqui, H.J.; Kawatra, S.K. Coal comminution and sizing. In The Coal Handbook. Towards Cleaner Production Vol. 1: Coal Production; Woodhead Publishing Limited: Cambridge, UK, 2013; pp. 240-262. [CrossRef]

13. Thomas, L.P. Coal resources and reserves. In The Coal Handbook. Towards Cleaner Production Vol. 1: Coal Production; Woodhead Publishing Limited: Cambridge, UK, 2013; pp. 80-106. [CrossRef]

14. Membrey, W. Coal sampling. In The Coal Handbook. Towards Cleaner Production Vol. 1: Coal Production; Woodhead Publishing Limited: Cambridge, UK, 2013; pp. 107-150. [CrossRef]

15. Miller, K. Coal analysis. In The Coal Handbook. Towards Cleaner Production Vol. 1: Coal Production; Woodhead Publishing Limited: Cambridge, UK, 2013; pp. 151-189. [CrossRef]

16. Juniper, L.; Schumacher, G. Advances in pulverised fuel technology: Understanding coal comminution, combustion and ash deposition. In The Coal Handbook. Towards Cleaner Production Vol. 1: Coal Production; Woodhead Publishing Limited: Cambridge, UK, 2013; pp. 312-351. [CrossRef]

17. Falcon, R. Coal petrography. In The Coal Handbook. Towards Cleaner Production Vol. 1: Coal Production; Woodhead Publishing Limited: Cambridge, UK, 2013; pp. 53-79. [CrossRef]

18. Bickert, G. Solid-liquid separation technologies for coal. In The Coal Handbook. Towards Cleaner Production Vol. 1: Coal Production; Woodhead Publishing Limited: Cambridge, UK, 2013; pp. 422-444. [CrossRef] 
19. Bethell, P.J. Economic factors affecting coal preparation: Plant design worldwide and case studies illustrating economic impact. In The Coal Handbook. Towards Cleaner Production Vol. 1: Coal Production; Woodhead Publishing Limited: Cambridge, UK, 2013; pp. 445-466. [CrossRef]

20. Galvin, K.P.; Iveson, S.M. Cleaning of coarse and small coal. In The Coal Handbook. Towards Cleaner Production Vol. 1: Coal Production; Woodhead Publishing Limited: Cambridge, UK, 2013; pp. 263-300. [CrossRef]

21. Honaker, R.Q.; Kohmuench, J.; Luttrell, G.H. Cleaning of fine and ultrafine coal. In The Coal Handbook. Towards Cleaner Production Vol. 1: Coal Production; Woodhead Publishing Limited: Cambridge, UK, 2013; pp. 301-346. [CrossRef]

22. Laskowski, J.S. Surface chemistry fundamentals in fine coal processing. In The Coal Handbook. Towards Cleaner Production Vol. 1: Coal Production; Woodhead Publishing Limited: Cambridge, UK, 2013; pp. 347-421. [CrossRef]

23. Vince, A. Post-treatment of coal. In The Coal Handbook. Towards Cleaner Production Vol. 1: Coal Production; Woodhead Publishing Limited: Cambridge, UK, 2013; pp. 467-528. [CrossRef]

24. Sitek, L.; Foldyna, J.; Martinec, P.; Klich, J.; Mašláň, M. On the preparation of precursors and carriers of nanoparticles by water jet technology. In Proceedings of the International Conference Water Jet. 2011-Research, Development, Applications, Ostravice, Czech Republic, 3-5 October 2011; pp. 255-271.

25. Lien, L. Advances in coal mining technology. In The Coal Handbook. Towards Cleaner Production Vol. 1: Coal Production; Woodhead Publishing Limited: Cambridge, UK, 2013; pp. 193-225. [CrossRef]

26. Mazurkiewicz, M. High pressure liquid jet as a tool for disintegrating organic and non-organic materials. Invent. Discl. 1984, 85 .

27. Mazurkiewicz, M. Method of Creating Ultra-Fine Particles of Materials Using High Pressure Mill. U.S. Patent 6,824,086, 30 November 2004.

28. Mazurkiewicz, M. Apparatus for Comminution of Solid Materials Using a Processor-Controlled Fluid Jet. U.S. Patent 6,435,435, 20 August 2002.

29. Cui, L.; An, L.; Gong, W. Effects of process parameters on the comminution capability of high pressure water jet mill. Int. J. Miner. Process. 2006, 81, 113-121. [CrossRef]

30. Cui, L.; An, L.; Gong, W. Optimizing process parameters of high pressure water jet mill. In Proceedings of the 8th Pacific Rim International Conference on Water Jet Technology, Qingdao, China, 10-12 October 2006; pp. 138-145.

31. Gong, W.; An, L.; Cui, L.; Liu, Y.; Xie, G. Desulfurization of coal based on high pressure water jet comminution. In Proceedings of the 2005 WJTA American Waterjet Conference, Houston, TX, USA, 21-23 August 2005.

32. Mei, F.; Weili, G.; Yufan, C. A new type of high pressure water jet mill. In Proceedings of the 10th American Waterjet Conference, Houston, TX, USA, 14-17 August 1999; p. 31.

33. Longlian, C.; Liqian, A.; Weili, G.; Hejin, J. A novel process for preparation of ultra-clean micronized coal by high pressure water jet comminution technique. Fuel 2007, 86, 750-757. [CrossRef]

34. Longlian, C.; Liqian, A.; Hejin, J. A novel process for preparation of an ultra-clean superfine coal-oil slurry. Fuel 2008, 87, 2296-2303. [CrossRef]

35. Sheng, F.; Hong, L.; Xiong, D. Research on ultrafine comminution of minerals by thermally assisted high pressure water jet. In Proceedings of the 2007 American WJTA Conference and Expo, Houston, TX, USA, 19-21 August 2007.

36. Galecki, G.; Akar, G.; Sen, S. New method of coal comminution to ultrafine size. Powder Metall. Min. 2013. [CrossRef]

37. Li, Y.; Galecki, G.; Sen, G.A.; Sen, S.; Zhang, Y. Application of the fractal theory for evaluating effects of coal comminution by waterjet. Int. J. Coal Sci. Technol. 2014, 1, 450-455. [CrossRef]

38. Galecki, G.; Sen, S.; Akar, G.; Li, Y. Parametric evaluation of coal comminution by waterjets. Int. J. Coal Prep. Util. 2013, 33, 36-46. [CrossRef]

39. Hanna, J.; Attia, Y. Advances in fine particles processing. In Proceedings of the International Symposium on Advances in Fine Particles Processing; Elsevier: New York, NY, USA; Amsterdam, The Netherlands; London, UK, 1990; ISBN 9781468479591.

40. Borkowski, P.J. Comminution of copper ores with the use of a high-pressure water jet. Energies 2020, 13, 6274. [CrossRef]

41. Pourghahramani, P.; Forssberg, E. Review of applied particle shape descriptors and produced particle shapes in grinding environments. The influence of comminution on the particle shape. Miner. Process. Extr. Metall. Rev. 2007, 26, 167-186. [CrossRef]

42. Erkan, S.; Tuncay, U. Effects of various parameters on ultrasonic comminution of coal in water media. Fuel Process. Technol. 2015, 137, 48-54. [CrossRef]

43. Yongzhi, X.; Hu, S.; Zili, Y.; Dayang, X. Microscopic damage field in coal induced by water jets. J. Loss Prev. Process. Ind. 2018, 56, 300-315. [CrossRef]

44. Li, Y.; Galecki, G.; Sen, G.A.; Sen, S. Effects of operating pressure and stand-off distance on coal comminution by waterjet. Physicochem. Probl. Miner. Process. 2017, 53, 394-401. [CrossRef]

45. Somani, A.; Nandi, T.K.; Pal, S.K.; Majumder, A.K. Pre-treatment of rocks prior to comminution-A critical review of present practices. Int. J. Min. Sci. Technol. 2017, 27, 339-348. [CrossRef] 